\title{
Cyanoacrylate embolism from gastric varices may lead to esophageal variceal rupture
}

\begin{abstract}
A 77-year-old woman diagnosed with hepatitis B presented with hematemesis. Esophagogastroduodenoscopy (EGD) showed esophageal varices with signs of red color, and tumor-like gastric varices with a white nipple ( $\bullet$ Fig. 1 a). For suspected recent bleeding, $4 \mathrm{ml}$ of a mixture of N-butyl-2-cyanoacrylate (Histoacryl) and Lipiodol (1:1 ratio) was injected into the gastric varices. Follow-up EGD 1 month later disclosed two ulcers on the esophageal varices at 36 and $34 \mathrm{~cm}$, respectively, from the incisor. Pathology examination of the removed protruding material at the center of the ulcer showed inflammatory cells mixed with a cyanoacrylate substance ( $\bullet$ Fig. $\mathbf{1}$ b,c).
\end{abstract}

A 57-year-old woman diagnosed with hepatitis B-related liver cirrhosis presented with massive tarry stool. EGD showed huge esophageal varices with signs of red color and active gastric variceal bleeding. For hemostasis, $4 \mathrm{ml}$ cyanoacrylate mixture was injected. Recurrent gastric variceal bleeding happened 1 week later, thus $6 \mathrm{ml}$ cyanoacrylate mixture was injected. However, tarry stool occurred again after 1 week, and EGD showed oozing from the disrupted esophageal variceal mucosa with protruding foreign materials ( $\bullet$ Fig. 2 ), which made ligation difficult. Therefore $1 \mathrm{ml}$ cyanoacrylate mixture was injected for hemostasis.

Endoscopic injection of cyanoacrylate to arrest gastric variceal bleeding has been widely used and is now considered more effective than sclerotherapy and band ligation [1]. However, despite the efficacy of endoscopic injection of cyanoacrylate, the serious but uncommon complications of distant and remote thromboembolism have been reported [2-4]. To our knowledge, these are the first cases of esophageal variceal embolism complicated by ulcer formation and bleeding after gastric variceal obliteration (GVO). In our pilot
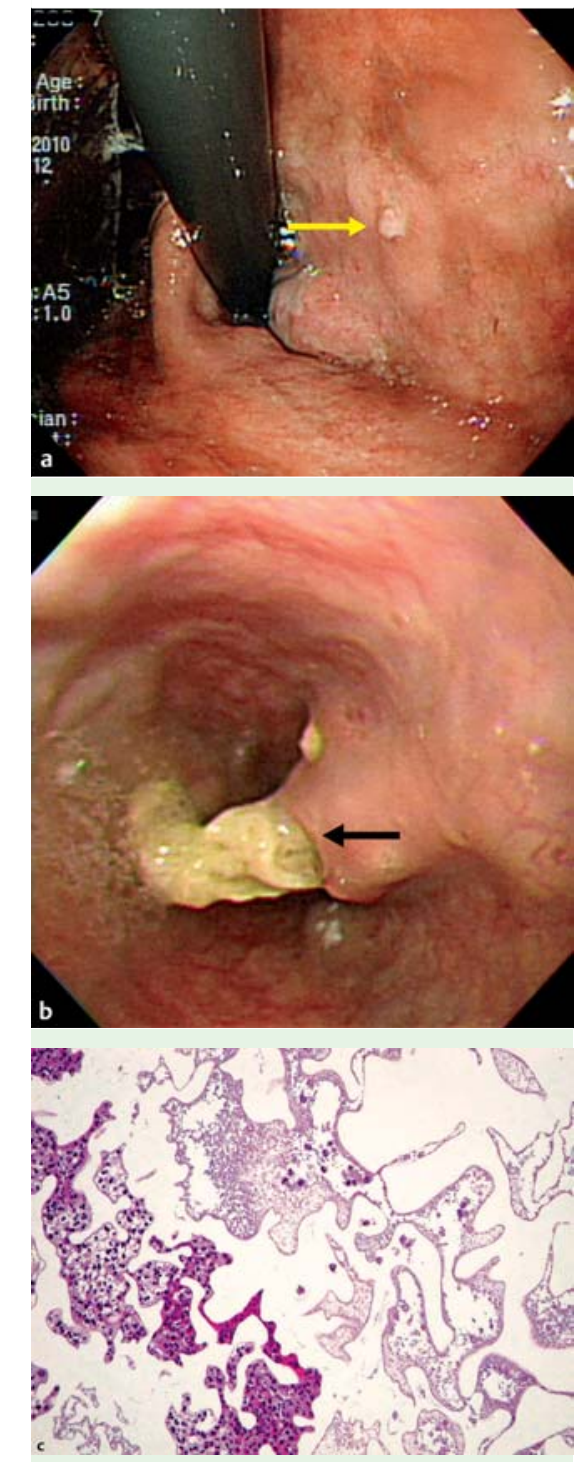

Fig. 1 Cyanoacrylate polymer migrates to the esophageal varices. a Before gastric variceal obliteration (GVO), esophagogastroduodenoscopy (EGD) shows a fibrin plug on the gastric varices (arrow). b EGD shows a protrusion of cyanoacrylate polymer from disrupted esophageal varices (arrow). c Microscopic findings reveal mixed inflammatory cells and eosinophilic fibrin-like materials, consistent with cyanoacrylate material.

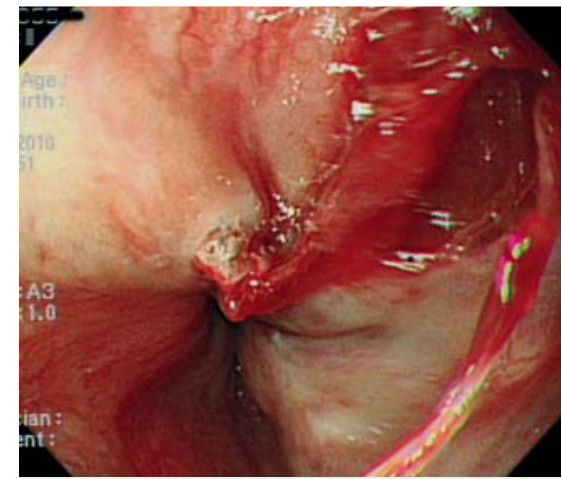

Fig. 2 Esophagogastroduodenoscopy (EGD) shows active esophageal variceal bleeding from the disrupted esophageal variceal mucosa.

study, the use of cyanoacrylate injection for gastric varices and concomitant banding ligation for esophageal varices was better than separate procedures to reduce re-bleeding [5]. The actual pathogenesis is unknown. From these two cases, postGVO cyanoacrylate embolism may be a possible pathogenesis that causes esophageal variceal bleeding and ligation failure. In summary, patients receiving GVO with large doses of cyanoacrylate may be at increased risk of esophageal variceal embolism and bleeding.

\section{Endoscopy_UCTN_Code_CPL_1AH_2AC}

\section{Competing interests: None}

\author{
P.-H. Chen ${ }^{1,2}$, M.-C. Hou ${ }^{1,2}$, H.-C. Lin ${ }^{1,2}$, \\ S.-D. Lee Len $^{1,2}$ \\ 1 Division of Gastroenterology, Depart- \\ ment of Medicine, Taipei Veterans \\ General Hospital, Taipei, Taiwan \\ 2 School of Medicine, National Yang-Ming \\ University, Taipei, Taiwan
}




\section{References}

1 Tan PC, Hou MC, Lin HC et al. A randomized trial of endoscopic treatment of acute gastric variceal hemorrhage: N-butyl-2-cyanoacrylate injection versus band ligation. Hepatology 2006; 43: 690-697

2 Chen WC, Hou MC, Lin HC et al. Bacteremia after endoscopic injection of N-butyl-2-cyanoacrylate for gastric variceal bleeding. Gastrointest Endosc 2001; 54: 214-218

3 Chang CJ, Shiau YT, Chen TL et al. Pyogenic portal vein thrombosis as a reservoir of persistent septicemia after cyanoacrylate injection for bleeding gastric varices. Digestion 2008; 78: 139-143
4 Tan YM, Goh KL, Kamarulzaman A et al. Multiple systemic embolisms with septicemia after gastric variceal obliteration with cyanoacrylate. Gastrointest Endosc 2002; 55: 276- 278

5 Chang CJ, Hou MC, Lin HC et al. The safety and probable therapeutic effect of routine use of antibiotics and simultaneously treating bleeding gastric varices by using endoscopic cyanoacrylate injection and concomitant esophageal varices with banding ligation: a pilot study. Gastrointest Endosc 2010; 71: $1141-1149$

\section{Bibliography}

DOI $10.1055 / \mathrm{s}-0030-1256256$

Endoscopy 2011; 43: E149-E150

(c) Georg Thieme Verlag KG Stuttgart · New York . ISSN 0013-726X

\section{Corresponding author}

M.-C. Hou, MD

Division of Gastroenterology

Department of Medicine

Veterans General Hospital-Taipei

No. 201, Sec 2, Shih-Pai Road

Taipei

Taiwan 11217

Fax: +886-2-28739318

mchou@vghtpe.gov.tw 